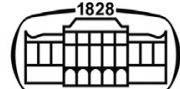

AKADÉMIAI KIADÓ

Journal of Behavioral

Addictions

10 (2021) 3, 767-778

DOl:

10.1556/2006.2021.00053

(c) 2021 The Author(s)

\section{FULL-LENGTH REPORT}

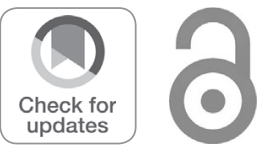

\title{
Identifying the central symptoms of problematic social networking sites use through network analysis
}

\author{
ANDREA SVICHER $\odot$, GIULIA FIORAVANTI $\odot$ and \\ SILVIA CASALE*
}

Department of Health Sciences, Section of Psychology, University of Florence, Italy

Received: January 19, 2021 • Revised manuscript received: April 29, 2021; July 12, 2021 • Accepted: July 25, 2021

Published online: August 25, 2021

\begin{abstract}
Background: Problematic social media use (PSMU) has received growing attention in the last fifteen years. Even though PSMU has been extensively studied, its internal structure is not fully understood. We used network analysis to evaluate which symptoms and associations between symptoms are most central to PSMU - as assessed by the Generalized Problematic Internet Use Scale-2 adapted for PSMU among undergraduates. Method: Network analysis was applied to a large gender-balanced sample of undergraduates ( $n=1344$ participants; $M=51.9 \%$; mean age $=22.50 \pm 2.20$ years). Results: The most central nodes in the network were the difficulty of controlling one's own use of social media, the tendency to think obsessively about going online, the difficulties in resisting the urge to use social media and the preference for communicating with people online rather than face-to-face. This last element was strongly associated with a general preference for online social interactions and the feeling of being more comfortable online. The network was robust to stability and accuracy tests. The mean levels of symptoms and symptom centrality were not associated. Conclusions: Deficient self-regulation and preference for online communication were the most central symptoms of PSMU, suggesting that these symptoms should be prioritized in theoretical models of PSMU and could also serve as important treatment targets for PSMU interventions.
\end{abstract}

\section{KEYWORDS}

behavioral addictions, technological addictions, Generalized Problematic Internet Use Scale-2, problematic social media use, problematic social networking sites use, network analysis

\section{INTRODUCTION}

The rapid growth in the popularity of social networking sites (SNS) has led to various empirical investigations on the potential benefits of their use, including the capacity to overcome permanent real-life issues (e.g., physical disabilities) and age- or work-related barriers (e.g., geographical distance to family members). Despite the various advantages of SNS, some authors in the past have raised the possibility that frequent SNS use might represent a technological addiction, i.e., a nonchemical (behavioral) addiction involving human-machine interaction (Griffiths, 1995), with women being more likely to exhibit problematic use than men (Su, Han, Jin, Yan, \& Potenza, 2019). Griffiths (2005) has argued that repeated behaviors that are characterized by salience, mood modification, tolerance, withdrawal, conflict, and relapse should be defined as addictive. Some authors (e.g., Shaffer, Hall, \& Vander Bilt, 2000) argue against this perspective by suggesting that an excessive use of SNS might be an expression of a pre-existing psychopathology (e.g., social anxiety or depression) rather than a primary disorder. Some others recommend a systematic assessment of the motivations to use SNS frequently. According to this perspective, excessive SNS use might reflect a temporary compensatory strategy to cope with transient negative states (Carbonell \& 
Panova, 2017; Kardefelt-Winther, 2014). Moreover, various authors argue that there is a need to clarify the specific beliefs, emotions, motivations or behaviors that characterize unregulated uses of substances or objects, in order to identify the pathways towards different addictive behaviors. Within this perspective, a number of studies (e.g., Assunção \& Matos, 2017; Casale \& Fioravanti, 2017; Fioravanti, Flett, Hewitt, Rugai, \& Casale, 2020; Marino, Vieno, Altoè, \& Spada, 2016) adapted the cognitive-behavioral model of problematic Internet use (Caplan, 2002, 2010; Davis, 2001) to the field of problematic SNS use (PSNS). Accordingly, the key symptoms of PSNSU are a preference for online social interactions (POSI), the motivation to use social media for mood regulation, deficient self-regulation of one's own use of social media, and negative outcomes arising from such use. POSI refers to the belief that online social media relationships are more secure, comfortable, effective, and less threatening than face-to-face interactions (Caplan, 2003). Mood regulation refers to the use of social media to reduce negative emotions (e.g., anxiety, feelings of isolation). Thus, social media use would act as a dysfunctional regulator of emotions. Deficient self-regulation is conceptualized as a construct that includes two different but closely related dimensions: cognitive preoccupation and compulsive use. Cognitive preoccupation refers to obsessive thinking patterns related to social media use, and compulsive use refers to an inability to control or regulate one's own use of social media. Last, the model highlights the importance of the negative consequences of social media use. This dimension refers to the extent to which individuals experience personal, social, academic, or professional problems as a result of their dysfunctional social media use (Caplan, 2010). In this model of PSNSU, POSI has central importance. It is considered the cognitive precursor of the use of social media to reduce negative feelings (i.e. the mood regulation component) and the inability to regulate one's own use of social media (i.e. the deficient self-regulation component). Hence, it is supposed to be a necessary cause of the development of problematic (i.e., unregulated) behavior, but at the same time, it already is a symptom of PSNSU. Compared to other approaches (e.g., the conceptualization leading to the development of the Bergen Social Media Addiction Scale), this model has not been developed deciding a-priori that PSNSU shares the core symptoms of traditional addictions (i.e., by merely adapting the substance addictions criteria, see Billieux, Schimmenti, Khazaal, Maurage, \& Heereen, 2015). Moreover, this model clarifies the relationships between beliefs, emotions, and maladaptive behaviors used to handle negative feelings, providing one of the few empirically-testable model in this field. Various empirical studies have provided empirical support for Caplan's model in the context of social media use (e.g., Assunção \& Matos, 2017; Marino et al., 2017), although the predictive power of the POSI dimension has been discussed (e.g., Moretta \& Buodo, 2018).

Despite the efforts made in Caplan (2010) and subsequent research to identify the most influential elements of the PSNSU construct, an analysis of the central structure of PSNSU is still lacking. Many previous researches (e.g.,
Gamez-Guadix, Orue, \& Calvete, 2013) have investigated PSNSU through the latent factor approach. This statistical perspective conceptualizes psychological phenomena as unobservable factors composed of single observable elements (Schmittmann et al., 2013). From this perspective, single elements have no causal influence on each other, and they simply reflect an underlying latent factor (Schmittmann et al., 2013). Hence, this approach cannot fully capture and articulate the ongoing process among the different aspects of PSNSU (Dalege et al., 2016; Schmittmann et al., 2013) or clarify whether some transdiagnostic symptoms of behavioral addiction (i.e., mood regulation, compulsive behavior, tolerance, and withdrawal) may more important to PSNSU than others, as suggested by Caplan's model.

An alternative to the latent factor approach, namely, the network approach, has been recently developed (Borsboom \& Cramer, 2013) and increasingly used (Contreras, Nieto, Valiente, Espinosa, \& Vazquez, 2019). According to this approach, the PSNSU construct does not necessarily arise from latent factors, but it may originate from the reciprocal action among its observable indicators (i.e., scale items; Dalege et al., 2016). This is also consistent with Caplan's cognitivebehavioral model of problematic Internet use. In this view, network analysis provides an estimate of the single elements of PSNSU (i.e., nodes) and determines the relationship of these elements supposed to be causally connected to one another (i.e., edges) (Borsboom \& Cramer, 2013). The presence of edges is thought to be a strong link between two elements (i.e., symptoms) that are likely to occur (or not occur) simultaneously either. Thus, such analysis might provide new opportunities to clarify the PSNSU construct since it identifies the most central nodes and edges functioning as the main pathways of the network (Marchetti, 2019) The identification of the core symptoms of PSU would also inform clinical decisions around what targets to pursue, like what has already been recently done in related fields of clinical psychology. For example, Levinson et al. (2017) have suggested that fear of weight gain should be the focus of treatments for bulimia nervosa as it was the central trait in their network. Huang, Lai, Xue, Zhang, and Wang (2020) explored the network of problematic smartphone use and found that loss of control is the key feature of this phenomenon, thus suggesting that preventing actions should focus on self-regulation.

The present study aims to investigate the PSNSU via network analysis. The Generalized Problematic Internet Use Scale-2 (GPIUS-2) (Caplan, 2010) was used because it represents the operationalization of the cognitive-behavioral model of PSNSU, and it was widely used in previous researches to measure PSNSU as a multidimensional phenomenon encompassing a preference for online social interactions, mood regulation, deficient self-regulation, and negative outcomes (e.g., Moretta \& Buodo, 2018; Fioravanti et al., 2020). Undergraduate participants were selected because the vast majority of the research has been conducted with this population since emerging adulthood is a time of intense and pervasive social media use (e.g., Jolliff, Moreno, \& D’Angelo, 2020; Kircaburun et al., 2019; Reer, Festl, \& Quandt, 2020; Shensa et al., 2017; Wong et al., 2020). 


\section{METHODS}

\section{Participants and procedures}

We used four datasets including 1,355 undergraduate students studying at different Italian public universities. Three out of four datasets were already partially used elsewhere to investigate $(i)$ differences in the PSNSU levels of grandiose and vulnerable narcissists (Casale, Fioravanti, \& Rugai, 2016), (ii) the association between shame experiences and PSNSU (Casale \& Fioravanti, 2017), and (iii) how maladaptive cognitions might contribute to PSNSU (Fioravanti et al., 2020). The internal structure of PSNSU was not investigated by these previous studies. In order to be eligible to participate, participants were required to be active users of at least one social media (e.g., Facebook, Twitter, and Instagram) defined as usage of at least $1 \mathrm{~h}$ per day (Varkaris \& Neuhofer, 2017). Data collection consisted of the GPIUS-2 questionnaire, and general information about the purposes of the study was announced to the participants beforehand. Participation was voluntary and anonymous, and confidentiality was guaranteed. No formative credits or remunerative rewards were given. Eleven participants were excluded from data analysis because of missing data that may have altered the structure of the network (Borsboom et al., 2017). The final sample consisted of 1,344 participants $(M=51.9 \%$; mean age $=22.5 \pm 2.2$ years old; range $18-33)$. Respondents reported using social media with an estimate average of $12.63 \mathrm{~h}$ online per week $(\mathrm{SD}=13.22)$.

\section{Measures}

The Generalized Problematic Internet Use Scale-2 (GPIUS-2) (Caplan, 2010) is a 15-item self-administered scale that assesses cognitions, behaviors, and negative consequences that arise because of the unique communicative context of the Internet (Caplan, 2010). The questionnaire was developed to tap the four constructs of Caplan's revised model already described in the Introduction section. The participants were asked to focus on their use of social media sites (i.e., Facebook, Twitter, and Instagram) to evaluate their degree of agreement with each item scored from 1 (definitely disagree) to 8 (definitely agree) (Caplan, 2010). Higher scores on items indicate higher levels of PSNSU. The majority of previous studies identify good psychometric properties with a stable four-factor structure for this scale (e.g., Assunção \& Matos, 2017; Barke, Nyenhuis, \& Kroner-Herwig, 2014; Caplan, 2010; Gamez-Guadix, Villa-George, \& Calvete, 2012, 2013; Pontes, Caplan, \& Griffiths, 2016). The Italian version (Fioravanti, Primi, \& Casale, 2013) has shown psychometric properties consistent with the original version.

\section{Statistical analysis}

Descriptive and preliminary analysis. The mean, standard deviation, kurtosis, and skewness of GPIUS-2 items were inspected. The R package psych 1.9.12.31 (Revelle, 2020) was used. The Italian version of the GPIUS-2 was found to have several departures from the assumption of multivariate normality (Fioravanti et al., 2013). Thus, polychoric correlations were estimated via a twofold approach (Epskamp \& Fried, 2018): 1) a threshold function (Muthén, 1984) as a data transformation function was used (seven thresholds to accommodate eight answering categories), and 2) the polychoric correlations between latent variables were estimated pairwise (Epskamp \& Fried, 2018; Rosseel et al., 2020). This procedure allows polychoric correlations to be reflective of a latent normally distributed score (Epskamp \& Fried, 2018). The lavaan 0.6-7 package (lavCor function) (Rosseel et al., 2020) was applied. The item redundancy test (i.e., two items "A" and "B" measure the same underlying construct) was given (Jones, 2020). Pairs of items that showed less than 25\% polychoric correlation statistically significantly different from all the cases were judged as redundant (Jones, 2020). Item informativeness was inspected via the mean standard deviations $\left(M_{S D}\right)$. An item below 2.5 SDs of $M_{S D}$ was considered to be poorly informative (Marchetti, 2019; Mullarkey, Marchetti, \& Beevers, 2019). The R package networktools 1.2.3 (Jones, 2020) was used.

Network analysis. In accordance with Epskamp and Fried (2018), the graphical network was estimated with the Extended Bayesian Information Criterion (EBIC) with the Least Absolute Shrinkage and Selection Operator (LASSO). EBIC LASSO network analysis provides a set of nodes corresponding to the GPIUS-2 items and edges corresponding to the link between two nodes (Epskamp \& Fried, 2018). The strength index was used to identify the most central nodes. The predictability index was assessed to evaluate how much of each node is accounted for by the neighboring nodes. Blue edges show positive associations, and red edges show negative associations. Edges that were more saturated and thicker indicated a stronger association (Epskamp \& Fried, 2018). The R packages qgraph 1.6.5 (Epskamp et al., 2020) and bootnet 1.2 (Epskamp \& Fried, 2019) were used. The local network properties were tested through the strength and predictability (Haslbeck \& Waldorp, 2018; Valente, 2012). Strength indicates the sum of the absolute weights of the edge connecting a node to all the other nodes (Valente, 2012). Predictability was the percentage of the variance of a particular node accounted for by all its related neighboring nodes (Haslbeck \& Waldorp, 2018). In the graphical network, percentages were displayed via pies around nodes (Epskamp et al., 2020). The $\mathrm{R}$ packages qgraph 1.6.5 (Epskamp et al., 2020) and mgm 1.2-9 (Haslbeck, 2020) were used.

The associations between informativeness, mean scores, strength, and predictability were inspected through Spearman rho correlations. The R package psych 1.9.12.31 (Revelle, 2020) was used. The robustness of the network was investigated through the correlation stability coefficient (CS coefficient), nonparametric bootstrapped difference tests for strengths and edges, and tests of the edge accuracy (Epskamp, Borsboom, \& Fried, 2018). A CS coefficient > 0.50 indicates a stable strength (Epskamp et al., 2018). Nonparametric bootstrapped difference tests for strengths 
and edges provided plots with gray boxes indicating no statistically significant difference and black boxes indicating a statistically significant difference (Epskamp et al., 2018). The central boxes displayed strength values or thicknesses of edges (Epskamp et al., 2018). The test of the edge accuracy provided a plotted curve of the $95 \%$ CIs, where larger CIs indicated lower precision and narrower CIs indicated higher precision (Epskamp et al., 2018). Differences were considered significant with 1000-bootstrap 95\% nonparametric CIs that did not contain zero (Epskamp et al., 2018). The R packages qgraph 1.6.5 (Epskamp et al., 2020) and bootnet 1.2 were used (Epskamp \& Fried, 2019).

To examine whether conceptually redundant item pairs (i.e., items 8 and 4; items 14 and 15; and items 6 and 10) influence the network structure of the GPIUS-2, the network model and the local structure indexes were re-estimated merging the redundant item pairs. Each conceptually redundant item pairs were merged via mean scores.

\section{Ethics}

The study procedures were carried out in accordance with the Declaration of Helsinki. All subjects were informed about the study and had to provide a signed written informed consent, including a privacy protection disclaimer in line with Italian and European laws on research activities. Approval to conduct the selected studies was obtained by the Director of the Department of Psychology of the University of Florence.

\section{RESULTS}

\section{Descriptive and preliminary statistics}

Table 1 shows the mean, standard deviation, skewness, and kurtosis of the GPIUS items. The skewness and kurtosis indices of 7 items ranged outside the values of -1 and 1 (Tabachnick \& Fidell, 2014), confirming that the departures from normality were not acceptable. Thus, a threshold function was implemented. Table 2 shows the zero-order polychoric correlations among the GPIUS-2 items obtained by applying the threshold function. No GPIUS-2 item was found to be redundant (i.e., $<25 \%$ of statistically significantly different correlations) or poorly informative (i.e., 2.5 $S D$ s below the mean level of informativeness, $M_{S D}=1.53 \pm$ 0.31 ). Hence, all items were included in the network analysis.

\section{Network estimation and local network properties}

Figure 1 shows the network model for the 15 items of the GPIUS-2. Network analysis showed that node \#10 (i.e., "I find it difficult to control my Internet use"), node \#11 (i.e., "I think obsessively about going online when I am offline"), and node \#12 (i.e., "When offline, I have a hard time trying to resist the urge to go online") were highly connected with the rest of the network.

Figures 2 and 3 show the centrality indexes (i.e., strengths) of the GPIUS-2 items. Item 10 (i.e., "I find it difficult to control my Internet use"; strength $=1.30$ ), item
Table 1. The GPIUS2 adapted for social media use: means, standard deviations, skewness, and kurtosis $(n=1,344)$

\begin{tabular}{|c|c|c|c|c|}
\hline Item Wording & M & SD & Skewness & Kurtosis \\
\hline $\begin{array}{l}\text { 1. Online social interaction is } \\
\text { more comfortable for me } \\
\text { than face-to-face } \\
\text { interaction }\end{array}$ & 2.25 & 1.59 & 1.41 & 1.68 \\
\hline $\begin{array}{l}\text { 2. When I haven't been online } \\
\text { for some time, I become } \\
\text { preoccupied with the } \\
\text { thought of going online. }\end{array}$ & 2.41 & 1.64 & 1.24 & 0.94 \\
\hline $\begin{array}{l}\text { 3. I prefer communicating } \\
\text { with people online rather } \\
\text { than face-to-face. }\end{array}$ & 1.87 & 1.43 & 2.11 & 4.65 \\
\hline $\begin{array}{l}\text { 4. I have used the Internet to } \\
\text { make myself feel better } \\
\text { when I was down. }\end{array}$ & 2.67 & 1.89 & 1.12 & 0.44 \\
\hline $\begin{array}{l}\text { 5. I have used the Internet to } \\
\text { talk with others when I was } \\
\text { feeling isolated. }\end{array}$ & 2.69 & 1.88 & 1.07 & 0.35 \\
\hline $\begin{array}{l}\text { 6. I have difficulty controlling } \\
\text { the amount of time I spend } \\
\text { online. }\end{array}$ & 2.91 & 2.08 & 0.97 & -0.08 \\
\hline $\begin{array}{l}\text { 7. I have missed social } \\
\text { engagements or activities } \\
\text { because of my Internet use. }\end{array}$ & 1.42 & 1.06 & 3.47 & 13.75 \\
\hline $\begin{array}{l}\text { 8. I have used the Internet to } \\
\text { make myself feel better } \\
\text { when I've felt upset. }\end{array}$ & 2.31 & 1.71 & 1.42 & 1.40 \\
\hline $\begin{array}{l}\text { 9. I would feel lost if I was } \\
\text { unable to go online. }\end{array}$ & 2.11 & 1.63 & 1.71 & 2.53 \\
\hline $\begin{array}{l}\text { 10. I find it difficult to control } \\
\text { my Internet use. }\end{array}$ & 2.19 & 1.70 & 1.59 & 1.91 \\
\hline $\begin{array}{l}\text { 11. I think obsessively about } \\
\text { going online when I am } \\
\text { offline. }\end{array}$ & 1.54 & 1.12 & 2.68 & 8.14 \\
\hline $\begin{array}{l}\text { 12. When offline, I have a } \\
\text { hard time trying to resist } \\
\text { the urge to go online. }\end{array}$ & 1.81 & 1.35 & 2.02 & 4.17 \\
\hline $\begin{array}{l}\text { 13. I prefer online social } \\
\text { interaction over face-to- } \\
\text { face communication. }\end{array}$ & 1.76 & 1.51 & 2.50 & 6.18 \\
\hline $\begin{array}{l}\text { 14. My Internet use has } \\
\text { created problems for me in } \\
\text { my life. }\end{array}$ & 1.52 & 1.20 & 2.97 & 9.37 \\
\hline $\begin{array}{l}\text { 15. My Internet use has made } \\
\text { it difficult for me to } \\
\text { manage my life. }\end{array}$ & 1.48 & 1.15 & 3.12 & 10.63 \\
\hline
\end{tabular}

11 (i.e., "I think obsessively about going online when I am offline"; strength $=1.30$ ), item 12 (i.e., "When offline, I have a hard time trying to resist the urge to go online"; strength $=$ 1.20 ), and item 3 ("I prefer communicating with people online rather than face-to-face"; strength $=1.20$ ) had the highest centrality indexes (Fig. 3) and were statically more central than the other nodes (Fig. 2).

The CS coefficient showed a very high value of 0.75 , indicating that the estimated strength was particularly robust and trustworthy. The predictability of each node 
Table 2. Zero-order polychoric correlations among the GPIUS-2 items with data transforming via threshold function $(n=1,344)$

\begin{tabular}{|c|c|c|c|c|c|c|c|c|c|c|c|c|c|c|c|}
\hline Item & 1 & 2 & 3 & 4 & 5 & 6 & 7 & 8 & 9 & 10 & 11 & 12 & 13 & 14 & 15 \\
\hline 1 & 1.00 & & & & & & & & & & & & & & \\
\hline 2 & 0.33 & 1.00 & & & & & & & & & & & & & \\
\hline 3 & 0.57 & 0.32 & 1.00 & & & & & & & & & & & & \\
\hline 4 & 0.31 & 0.38 & 0.33 & 1.00 & & & & & & & & & & & \\
\hline 5 & 0.31 & 0.37 & 0.29 & 0.55 & 1.00 & & & & & & & & & & \\
\hline 6 & 0.18 & 0.39 & 0.15 & 0.36 & 0.27 & 1.00 & & & & & & & & & \\
\hline 7 & 0.16 & 0.25 & 0.30 & 0.26 & 0.22 & 0.26 & 1.00 & & & & & & & & \\
\hline 8 & 0.27 & 0.32 & 0.27 & 0.68 & 0.51 & 0.32 & 0.30 & 1.00 & & & & & & & \\
\hline 9 & 0.26 & 0.44 & 0.25 & 0.36 & 0.32 & 0.45 & 0.28 & 0.38 & 1.00 & & & & & & \\
\hline 10 & 0.22 & 0.38 & 0.24 & 0.34 & 0.24 & 0.66 & 0.36 & 0.33 & 0.54 & 1.00 & & & & & \\
\hline 11 & 0.17 & 0.41 & 0.24 & 0.30 & 0.22 & 0.34 & 0.42 & 0.28 & 0.47 & 0.50 & 1.00 & & & & \\
\hline 12 & 0.23 & 0.44 & 0.28 & 0.34 & 0.30 & 0.38 & 0.30 & 0.31 & 0.50 & 0.56 & 0.63 & 1.00 & & & \\
\hline 13 & 0.46 & 0.26 & 0.57 & 0.27 & 0.22 & 0.16 & 0.24 & 0.26 & 0.21 & 0.27 & 0.30 & 0.31 & 1.00 & & \\
\hline 14 & 0.14 & 0.23 & 0.22 & 0.25 & 0.25 & 0.26 & 0.38 & 0.25 & 0.22 & 0.31 & 0.39 & 0.31 & 0.25 & 1.00 & \\
\hline 15 & 0.14 & 0.20 & 0.21 & 0.23 & 0.17 & 0.26 & 0.38 & 0.25 & 0.26 & 0.34 & 0.43 & 0.39 & 0.29 & 0.61 & 1.00 \\
\hline
\end{tabular}
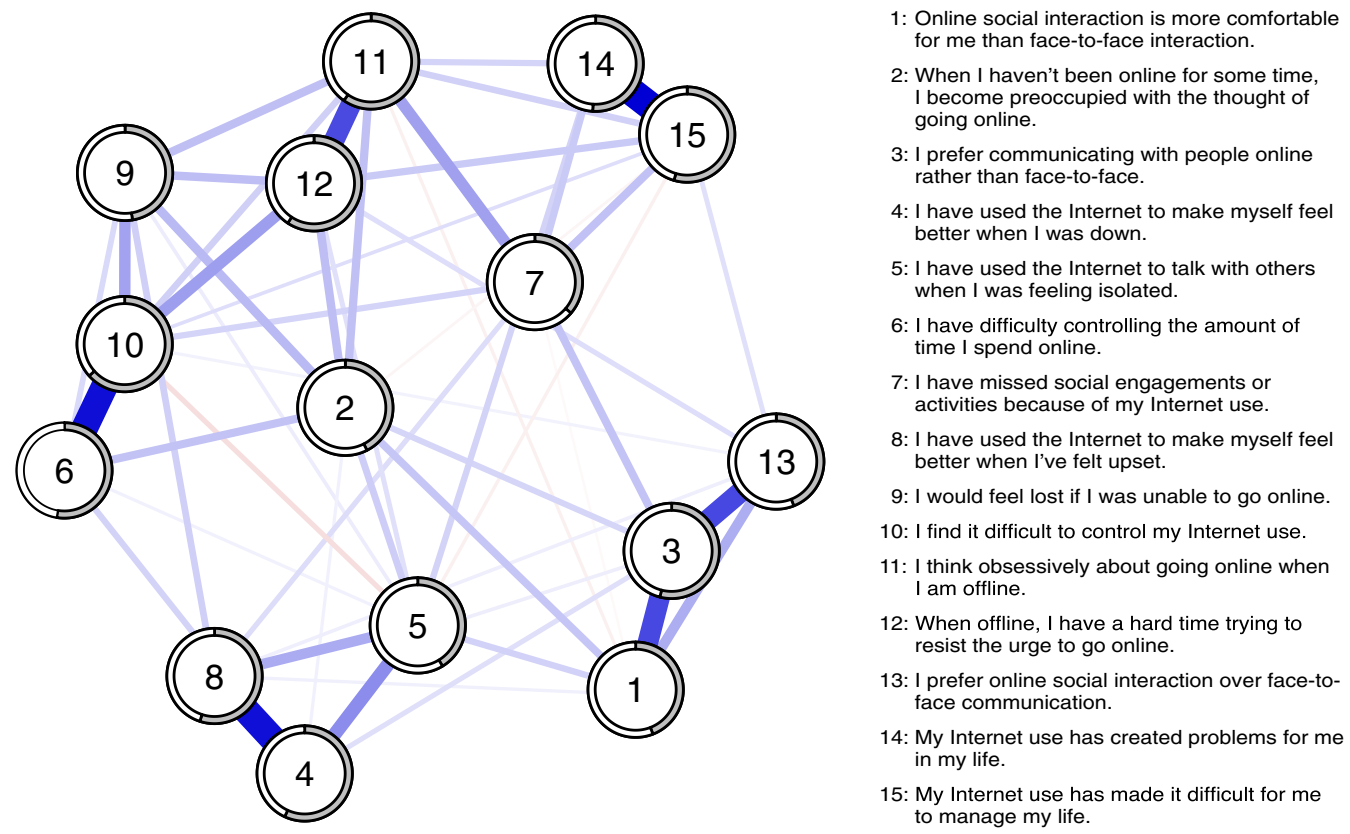

Fig. 1. Network model for the 15 items of the GPIUS-2 $(n=1,344)$

ranged from 0.37 (node \#7) to 0.64 (node \#10) with $51 \%$ of each node variance potentially accounted for by its neighboring nodes $\left(M_{\text {predictability }}=0.51 \pm 0.08\right)$. Strength and predictability were found to be not correlated with item variability $\left(r_{s}=-0.01,95 \% \mathrm{CI}[-0.59,0.61]\right.$; and $r_{s}=0.03$, $95 \%$ CI $[-0.59,0.59]$, respectively) or with the items' mean levels $\left(r_{s}=-0.02,95 \% \mathrm{CI}[-0.51,0.54]\right.$; and $r_{s}=0.04,95 \%$ CI $[-0.61,0.57]$, respectively).

\section{Accuracy and edge comparisons}

Figure 4 shows the edge accuracy test. This result indicated that the precision of the 105 edges was excellent. Thus, the network model was deemed to be accurate.

Figure 5 shows the nonparametric bootstrapped difference test for edges. The analysis revealed that six edges were stronger and statistically significantly different than the majority of the network edges.

Namely, these six edges were the following: the edge connecting node \#1 ("Online social interaction is more comfortable for me than face-to-face interaction") and \#3 ("I prefer communicating with people online rather than faceto-face"), the edge connecting node \#3 and \#13 ("I prefer online social interaction over face-to-face communication"), the edge connecting node \#4 ("I have used the Internet to make myself feel better when I was down") and \#8 ("I have used the Internet to make myself feel better when I've felt upset"), the edge connecting node \#6 ("I have difficulty controlling the amount of time I spend online") and \#10 ("I find it difficult to control my Internet use"), the edge connecting node \#11 ("I think obsessively about going online when I am offline") and \#12 ("When offline, I have a hard 


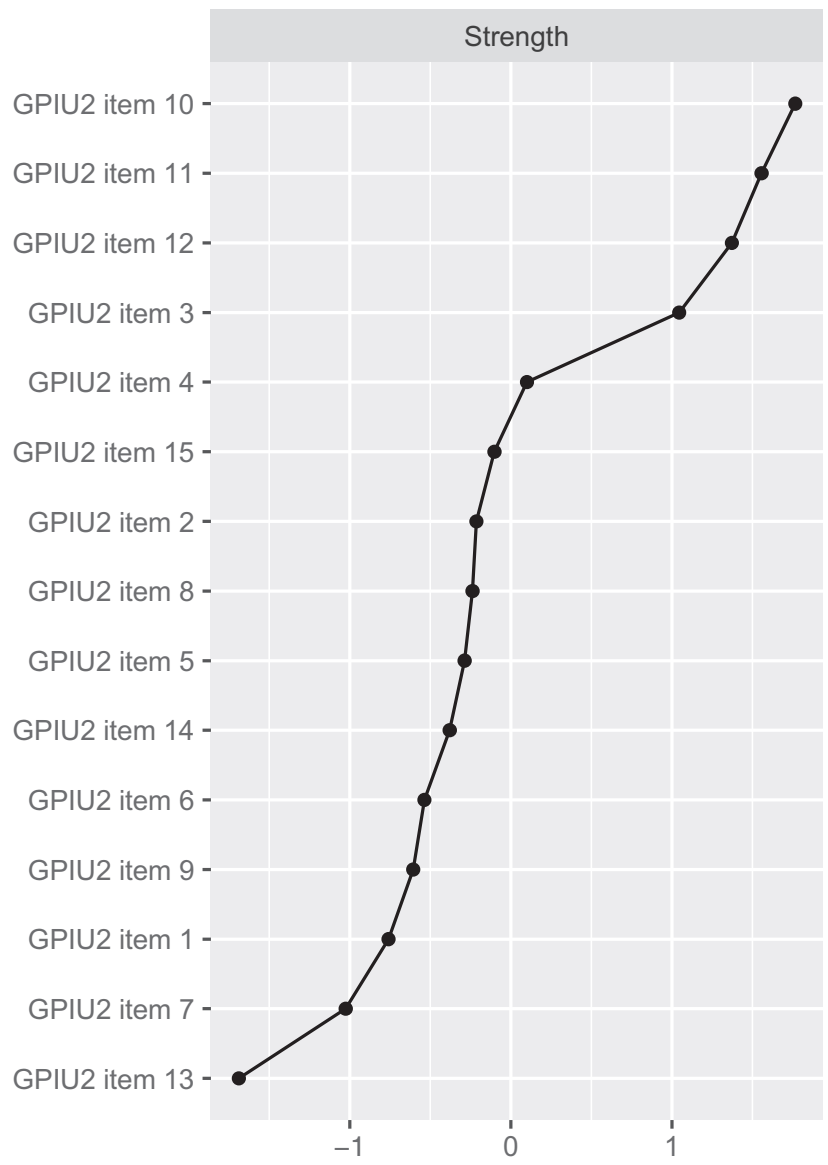

Fig. 2. The Generalized Problematic Internet Use Scale-2: strength scores (centrality) for the 15 items, shown as standardized $z$ scores

$$
(n=1,344)
$$

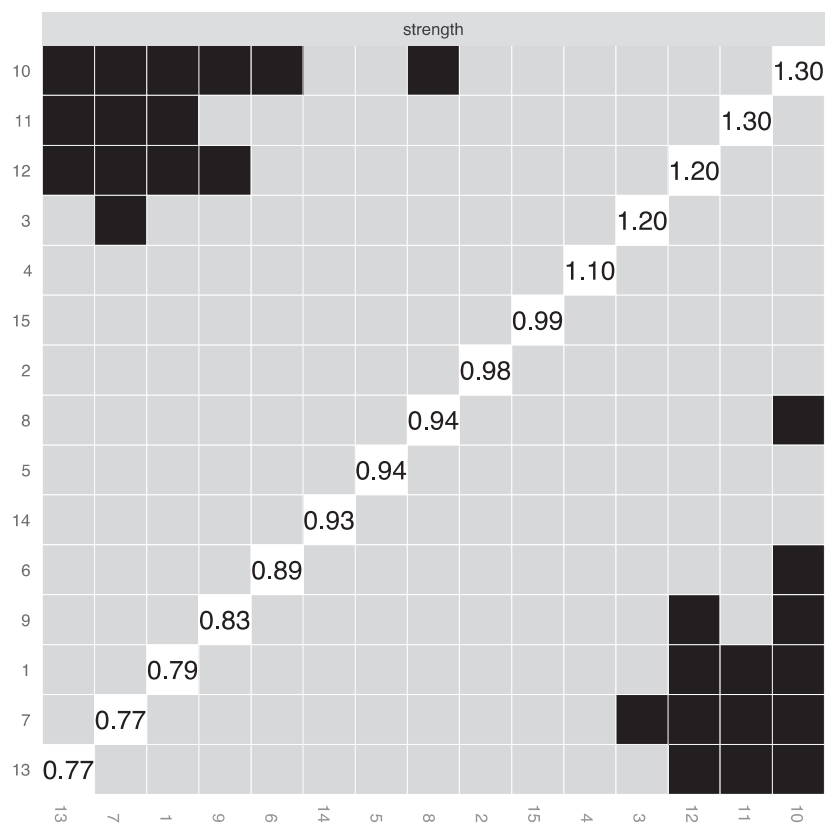

Fig. 3. The Generalized Problematic Internet Use Scale-2: nonparametric bootstrapped difference test for strength time trying to resist the urge to go online"), and the edge connecting node \#14 ("My Internet use has created problems for me in my life") and \#15 ("My Internet use has made it difficult for me to manage my life") (Fig. 5).

The re-estimated network model with the conceptually redundant items merged showed properties in line with the original network (Figures S1-S3). The most connected nodes well reflected those identified for the original scale (i.e., item 11, item 12, and item 10), and the network structure of the GPIUS-2 with the conceptually redundant item pairs merged revealed connections between nodes similar to those observed in the original structure.

\section{DISCUSSION}

Problematic social networking sites use (PSNSU) has been conceptualized from a variety of theoretical perspectives. Despite some consensus on its constituent components, their roles remain a subject of controversy. Little is known about PSNSU symptoms' structure and how the symptoms interact with one another. In the current study, we used network analysis to extend our understanding of this phenomenon and complement previous research relying on the latent factor approach.

The first central node was represented by the deficient self-regulation in terms of difficulties in controlling one's own use of SNS (node \#10), unsuccessful efforts to resist when trying (node \#12), and obsessive thinking to go online (node \#11). Notably, these high centrality nodes were strongly associated with each other, highlighting a pathway of core symptoms that have been supposed to be linked to deficiency in the reflective-inhibitory prefrontal brain system as it is implicated in the abilities to actively stop a behavioral response (He, Turel, \& Bechara, 2017). This is a central issue as the way of determining whether problematic behaviors need to be considered addictive is to compare them against clinical and biological criteria for established chemical addictions (Alavi et al., 2012), and future studies should help in clarifying neurobiological similarities between PSNSU and recognized addictive behaviors. The network structure also revealed that the preference for online communication (node \#3) showed high centrality. Moreover, it also shows a strong connection with the preference for online social interactions (node \#13) and the perception of them as more comfortable (node \#1). Keeping in mind that centrality does not necessarily imply causality (see Dablander \& Hinne, 2019), our findings support that the preference for online communication may play a particularly important role in the development of PSNSU. The first main result (i.e., the high centrality of deficient self-regulation) might be interpreted as a commonality between PSNSU and other addictions (i.e., the degree to which PSNSU shares some key aspects with well-established addictions), whereas the second main finding (i.e., the high centrality of the preference for online communication) seems to highlight the differences between them (i.e., the degree to which PSNSU shows key peculiar aspects). 


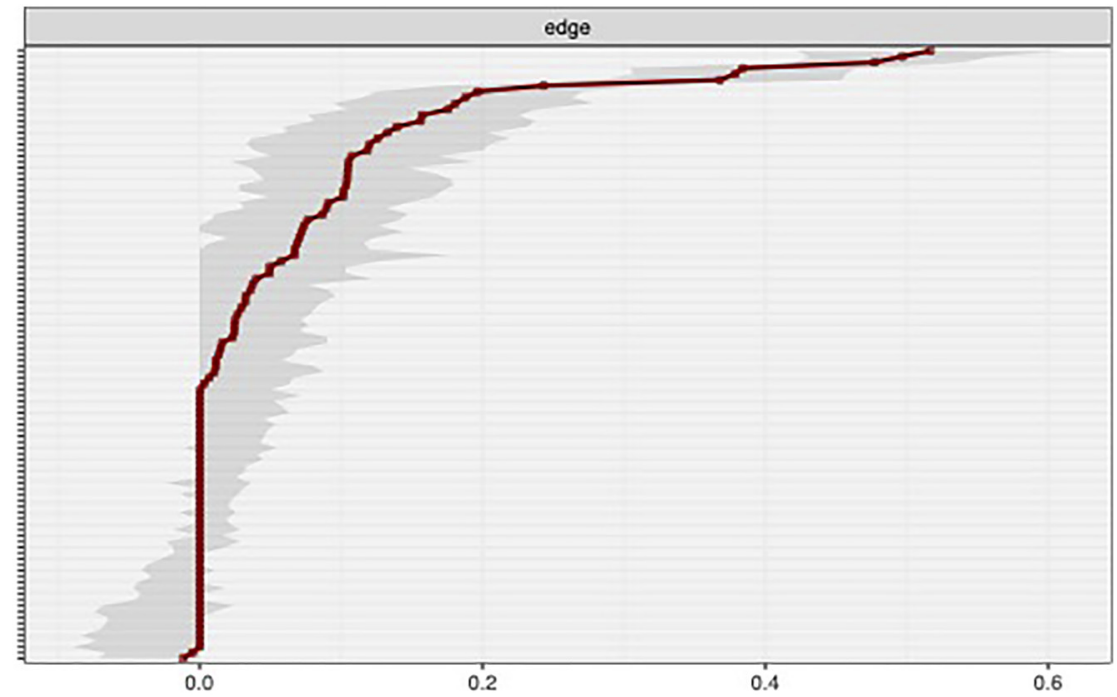

Fig. 4. The Generalized Problematic Internet Use Scale-2: nonparametric bootstrapped confidence intervals of estimated edges

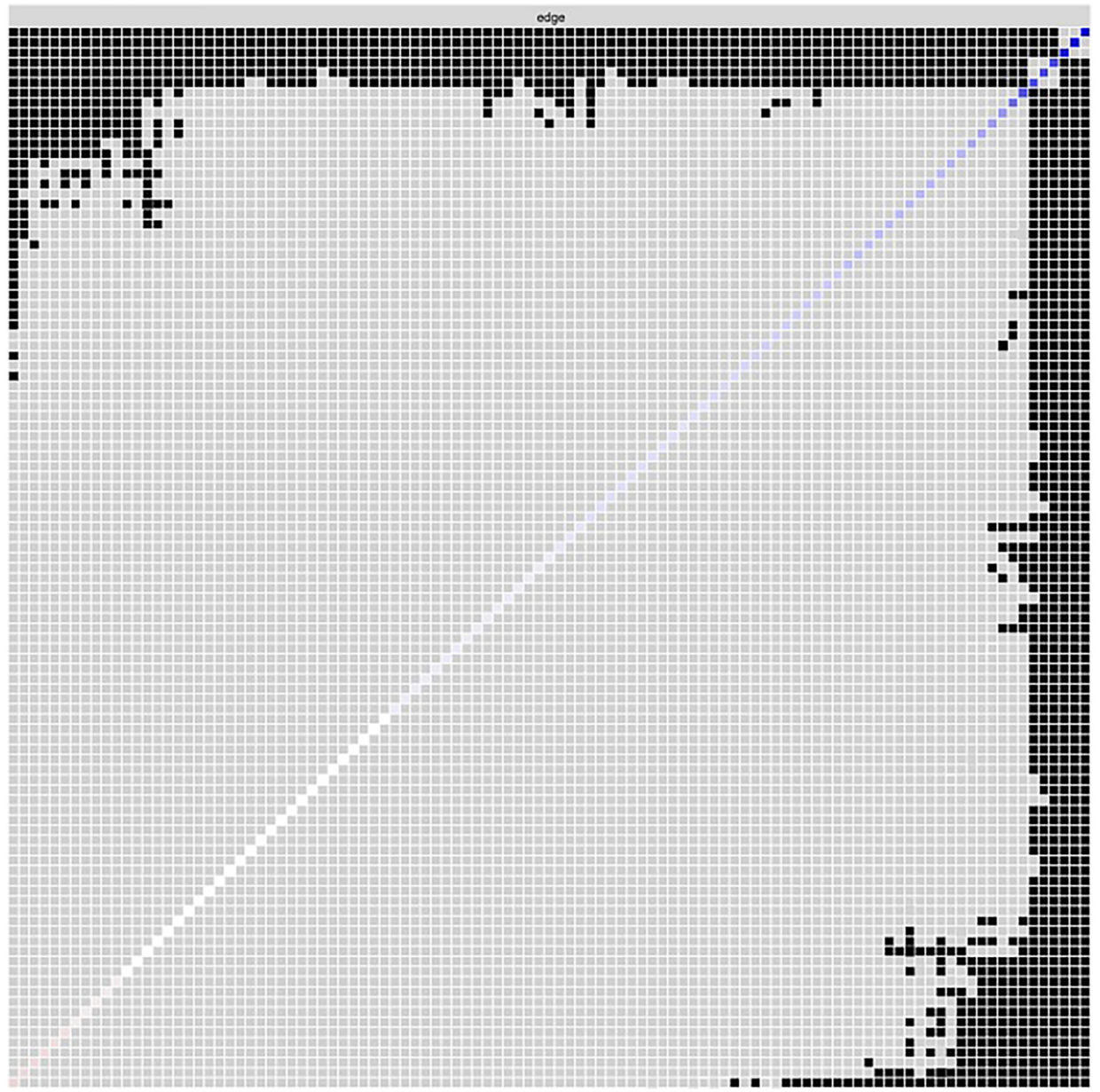

Fig. 5. The Generalized Problematic Internet Use Scale-2: Nonparametric bootstrapped difference test for edges

These results, as a whole, have at least three implications. First, they give further support to the cognitive-behavioral model proposed by Caplan (2010), since his model conceptualized the preference for online communication as the key symptom, defining it as the cognitive precursor of all the other PSNSU components (i.e., the tendency to use the web for regulating negative mood states, the compulsive use of the web, and the presence of negative outcomes in real life). 
Second, this result suggests that adapting the substance addiction criteria to the so-called "new addictions" without considering its specific symptoms (be them beliefs or behaviors) or pathways paints only half of the picture, as already suggested elsewhere (see Billieux et al., 2015). Consequently, screening tools that have been developed simply adapting the traditional substance abuse criteria, such as the Bergen Facebook Addiction Scale (Andreassen, Torsheim, Brunborg, \& Pallesen, 2012) and the Bergen Social Media Addiction Scale (Andreassen et al., 2016), might fail to capture some core elements of PSNSU (i.e., the preference for online communication). This point is of primary importance considering that the two abovementioned questionnaires are the most commonly used self-reported measures to assess Facebook addiction and social media addiction, respectively. Third, this finding suggests that reducing the risk factors for the preference for online communication could be a way to reduce PSNSU. For instance, in keeping with hyperpersonal theory (Walther, 1996), which argues that CMC's unique properties (i.e., diminished verbal and nonverbal cues and an enhanced probability of impression management) represent an appealing advantage for those with interpersonal difficulties, previous research highlights that loneliness (Ye \& Lin, 2015), fear of negative evaluation (Casale, Fioravanti, Flett, \& Hewitt, 2014), shame experiences (Casale \& Fioravanti, 2017) and narcissistic traits (Andreassen, Pallesen, \& Griffiths, 2017) might put a person at a risk for PSNSU.

The preference for online communication (node \#3) was also connected with anxious worrying about being online (node \#2) and missing social engagements/activities (node \#7). This is consistent with the cognitive-behavioral model of PSNSU (Caplan, 2010) and subsequent empirical studies (e.g., Assunção \& Matos, 2017; Moretta \& Buodo, 2018; de Veiga et al., 2019) indicating that the preference for online communication is related to the cognitive preoccupation with one's own social media use. Taken together, these pieces of evidence regarding the second central node expand previous findings by showing the centrality of the preference for online communication (node \#3) and suggest that this symptom could be used as a screening indicator for POSI. POSI might also help in distinguishing between related potential behavioral addictions considering that a very recent study has shown that the lack of control is the key element in a network analysis of problematic smartphone use, whilst preference for online social interactions shows low centrality (Huang et al., 2020). As our findings on PSNSU are similar with respect to the first result but different regarding the role of POSI, one might argue that the preference for online social interactions might be the fundamental symptom to distinguish between different Internet use disorders. Future studies should also clarify whether our results are generalizable or not to specific SNSs. One might argue that results concerning the high centrality of the lack of control in one's own use of SNS should show high stability because deficient self-regulation is one of the core symptoms of addictive behaviors. Conversely, we cannot exclude that other symptoms (e.g., a high need for self-presentation) might be more central when it comes to SNSs used solely for photo and video sharing (i.e., Instagram).
Some other results might be of interest. Obsessive thinking to go online (node \#11) was also related to negative outcomes (nodes \#7, \#14, and \#15). This is in line with Caplan and High (2006) who reported that the association between problematic use and negative outcomes is more pronounced when cognitive preoccupation is present. This result suggests that even though targeting the central nodes does not certainly lead to a change in the network structure (Fried et al., 2018), an effective clinical strategy could be focusing on obsessive thinking. In line with this, promising interventions addressing unhelpful cognitive styles (e.g., desire thinking, thought suppression, rumination, or worry) were recently developed in the field of addictive behaviors (Spada, Caselli, Nikčević, \& Wells, 2015).

It is not surprising that difficulty controlling the amount of time spent on social media (node \# 6) showed low centrality since the literature emphasized that time spent on social media per se is not an indicator of pathological use (Caplan, 2003, 2010; Griffiths, 2009, 2010). However, the distance from the pathway and low centrality of mood regulation elements (nodes $\# 4, \# 5$, and $\# 8$ ) are in contrast with the literature (e.g., Lim, Cheung, Kho, \& Tang, 2020; Moretta \& Buodo, 2018). his could be explained by the fact that our sample is composed of healthy subjects who could have low levels of negative emotions to handle. Another possible interpretation of our results involves the items which make up the mood regulation subscale. Two out of three items assess the motivation to use the Internet to regulate broad negative emotions (e.g., "I have used....when I was down" and "I have used....when I have felt upset", item 4 and item 8 , respectively). One might suppose that motivation to regulate social emotions (e.g., fear of missing out, shame, fear of being negatively evaluated, envy) might be more determinant in explaining the unregulated use of social networking sites. That is, feeling down or upset might motivate ad individual to a more generalized (i.e., nondifferentiated) use of the Internet, whilst interpersonallybased emotions (especially fears) might be involved with PSNS. Future studies might want to modify the three items assessing the mood regulation motivation in order to test whether these elements might show higher centrality than that found in the current study.

Both node centrality and predictability were not related to item scores and variability. This is in line with the network approach, which underlines the need to analyze not only the mere intensity of elements but also its specific roles in the network structure (Marchetti, 2019; Mullarkey et al., 2019). Last, on average, a high percentage (i.e., 51\%) of node variance is explained by the neighboring nodes (i.e., predictability). Thus, constituent components of PSNSU were satisfactorily accounted for, in accordance with its unitary conceptualization (Caplan, 2010).

This study has limitations and strengths. First, the GPIUS2 items were not modified, even because the GPIUS2 already includes items related to the social aspects of the Internet (e.g., Item 1: "Online social interactions are more comfortable for me than face-to-face interactions). Participants were simply asked to focus on their use of social 
networking sites (i.e., Facebook, Twitter, and Instagram) when answering the items like what was done in other studies in this field (e.g., Rothen et al., 2018). Future research might want to compare the psychometric characteristics of the GPIUS2 version used in the present study with a GPIUS2 version with modified items (e.g., by replacing the words "online" or "Internet" with "SNS; see, for example, Assunção \& Matos, 2017)." Second, healthy young adult subjects were enrolled. Thus, the results cannot be generalized to adolescents, older adults, and clinical populations. Third, the data were cross-sectional, which limits the ability to draw directionality among items. This is only an apparent limitation since the value added by the network analysis generated several empirically testable hypotheses. Future research should attempt to clarify the causal/temporal relationship of PSNSU elements via experimental manipulation or ecological momentary assessment methods.

The main strength is that network analysis was applied for the first time to evaluate the central symptoms of PSNSU through state-of-the-art guidelines (Epskamp et al., 2018; Epskamp \& Fried, 2018). We used a statistical approach in which PSNSU arises out from the interactions of symptoms. This process has allowed us to show the network structure with nodes and edges describing central symptoms (i.e., deficient self-regulation and the preference for online communication), peripherical symptoms (i.e., mood regulation motivation - as assessed by the GPIUS2 -, and negative outcomes), and their reciprocal relationship. Such perspective is essential to obtain a better understanding of the central symptoms of PSNSU, as this is a field of study that has been characterized by confirmatory approaches (both theoretically and statistically) in which PSNSU is a priori considered as an addictive behavior. Through the network approach, we have shown that the central nodes of the network address addiction-like symptoms, on the one hand, and cognitive symptoms that might be peculiar to PSNSU (i.e., the preference for online communication), on the other hand.

\section{CONCLUSIONS}

In brief, network analysis revealed a central pathway of addiction-like symptoms, agreeing with all the theoretical models in the field suggesting some clinical similarities between PSNSU and well-established addictions (Shapira et al., 2003; Griffiths, 2013). The current study also shows that the preference for online communication is among the central symptoms of PSNSU, and it should be considered a potential target for treatment. The results also indicated that obsessive thinking to go online was connected with other addictionlike symptoms and negative outcomes, thus representing a potential target for effective psychological interventions.

Funding sources: This research did not receive any specific grant from funding agencies in the public, commercial, or not-for-profit sectors.
Authors' contributions: Andrea Svicher: writing - original draft, methodology, formal analysis. Giulia Fioravanti: writing - review \& editing. Silvia Casale: conceptualization, supervision, writing - original draft, writing - review \& editing.

Conflict of interest: Declarations of interest: none.

\section{SUPPLEMENTARY MATERIAL}

Supplementary data to this article can be found online at https://doi.org/10.1556/2006.2021.00053.

\section{REFERENCES}

Alavi, S. S., Ferdosi, M., Jannatifard, F., Eslami, M., Alaghemandan, H., \& Setare, M. (2012). Behavioral addiction versus substance addiction: Correspondence of psychiatric and psychological views. International Journal of Preventive Medicine, 3(4), 290294. Retrieved from https://www.ncbi.nlm.nih.gov/pmc/ articles/PMC3354400/.

Andreassen, C. S., Billieux, J., Griffiths, M., Kuss, D., Demetrovics, Z., Mazzoni, E., \& Pallesen, S. (2016). The relationship between addictive use of social media and video games and symptoms of psychiatric dis-orders: A large-scale cross-sectional study. Psychology of Addictive Behaviors, 30(2), 252-326. https://doi.org/ 10.1037/adb0000160.

Andreassen, C. S., Pallesen, S., \& Griffiths, M. D. (2017). The relationship between addictive use of social media, narcissism, and self-esteem: Findings from a large national survey. Addictive Behaviors, 64, 287-293. https://doi.org/10.1016/j.addbeh. 2016.03.006.

Andreassen, C. S., Torsheim, T., Brunborg, G. S., \& Pallesen, S. (2012). Development of a Facebook addiction scale. Psychological Reports, 110(2), 501-517. https://doi.org/10.2466/02.09. 18.pr0.110.2.501-517.

Assunção, R. S., \& Matos, P. M. (2017). The generalized problematic internet use scale 2: Validation and test of the model to Facebook use. Journal of Adolescence, 54, 51-59. https://doi.org/ 10.1016/j.adolescence.2016.11.007.

Barke, A., Nyenhuis, N., \& Kroner-Herwig, B. (2014). The German version of the generalized pathological internet use scale 2: A validation study. Cyberpsychology Behavior and Social Networking, 17(7), 474-482. https://doi.org/10.1089/cyber.2013. 0706.

Billieux, J., Schimmenti, A., Khazaal, Y., Maurage, P., \& Heeren, A. (2015). Are we overpathologizing everyday life? A tenable blueprint for behavioral addiction research. Journal of Behavioral Addictions, 4(3), 119. https://doi.org/10.1556/2006.4.2015.009.

Borsboom, D., \& Cramer, A. O. J. (2013). Network analysis: An integrative approach to the structure of psychopathology. Annual Review of Clinical Psychology, 9(1), 91-121. https://doi. org/10.1146/annurev-clinpsy-050212-185608.

Borsboom, D., Fried, E. I., Epskamp, S., Waldorp, L. J., van Borkulo, C. D., van der Maas, H. L. J., \& Cramer, A. O. J. (2017). False alarm? A comprehensive reanalysis of "evidence that 
psychopathology symptom networks have limited replicability" by Forbes, Wright, Markon, and Krueger (2017). Journal of Abnormal Psychology, 126(7), 989-999. https://doi.org/10.1037/ abn0000306.

Caplan, S. E. (2002). Problematic Internet use and psychosocial well-being: Development of a theory- based cognitive-behavioral measurement instrument. Computers in Human Behavior, 18(5), 553-575. https://doi.org/10.1016/s0747-5632(02)00004-3.

Caplan, S. E. (2003). Preference for online social interaction: A theory of problematic Internet use and psychosocial well-being. Communication Research, 30(6), 625-648. https://doi.org/10. 1177/0093650203257842.

Caplan, S. E. (2010). Theory and measurement of generalized problematic Internet use: A two-step approach. Computers in Human Behavior, 26(5), 1089-1097. https://doi.org/10.1016/j. chb.2010.03.012.

Caplan, S. E., \& High, A. C. (2006). Beyond excessive use: The interaction between cognitive and behavioral symptoms of problematic Internet use. Communication Research Reports, 23(4), 265-271. https://doi.org/10.1080/08824090600962516.

Carbonell, X., \& Panova, T. (2017). A critical consideration of social networking sites' addiction potential. Addiction Research \& Theory, 25(1), 48-57. https://doi.org/10.1080/16066359.2016. 1197915.

Casale, S., \& Fioravanti, G. (2017). Shame experiences and problematic social networking sites use: An unexplored association. Clinical Neuropsychiatry, 14(1), 44-48. Retrieved from https:// www.clinicalneuropsychiatry.org/download/shame-experiencesand-problematic-social-networking-sites-use-an-unexploredassociation/.

Casale, S., Fioravanti, G., Flett, G. L., \& Hewitt, P. L. (2014). From socially prescribed perfectionism to problematic use of internet communicative services: The mediating roles of perceived social support and the fear of negative evaluation. Addictive Behaviors, 39(12), 1816-1822. https://doi.org/10.1016/j.addbeh.2014. 06.006.

Casale, S., Fioravanti, G., \& Rugai, L. (2016). Grandiose and vulnerable narcissists: Who is at higher risk for social networking addiction? Cyberpsychology Behavior and Social Networking, 19(8), 510-515. https://doi.org/10.1089/cyber.2016. 0189.

Contreras, A., Nieto, I., Valiente, C., Espinosa, R., \& Vazquez, C. (2019). The study of psychopathology from the network analysis perspective: A systematic review. Psychotherapy and Psychosomatics, 88(2), 71-83. https://doi.org/10.1159/000497425.

Dablander, F., \& Hinne, M. (2019). Node centrality measures are a poor substitute for causal inference. Scientific Reports, 9, 6846. https://doi.org/10.1038/s41598-019-43033-9.

Dalege, J., Borsboom, D., van Harreveld, F., van den Berg, H., Conner, M., \& van der Maas, H. L. J. (2016). Toward a formalized account of attitudes: The Causal Attitude Network (CAN) model. Psychological Review, 123(1), 2-22. https://doi. org/10.1037/a0039802.

Davis, R. A. (2001). A cognitive-behavioral model of pathological Internet use. Computers in Human Behavior, 17(2), 187-195. https://doi.org/10.1016/S0747-5632(00)00041-8.

Epskamp, S., Borsboom, D., \& Fried, E. I. (2018). Estimating psychological networks and their accuracy: A tutorial paper.
Behavior Research Methods, 50(1), 195-212. https://doi.org/10. 3758/s13428-017-0862-1.

Epskamp, S., Costantini, G., Haslbeck, J., Isvoranu, A., Cramer, A. O. J., Waldorp, L. J., ... Borsboom, D. (2020). Qgraph. Graph plotting methods, psychometric data visualization and graphical model estimation ( $\mathrm{R}$ package version 1.9.12.31) [Computer software]. Retrieved from https://cran.r-project.org/web/ packages/qgraph/qgraph.pdf.

Epskamp, S., \& Fried, E. I. (2018). A tutorial on regularized partial correlation networks. Psychological Methods, 23(4), 617-634. https://doi.org/10.1037/met0000167.

Epskamp, S., \& Fried, E. I. (2019). Bootnet. Bootstrap methods for various network estimation routines ( $\mathrm{R}$ package version 1.2) [Computer software]. Retrieved from https://cran.r-project.org/ web/packages/bootnet/bootnet.pdf.

Fioravanti, G., Flett, G., Hewitt, P., Rugai, L., \& Casale, S. (2020). How maladaptive cognitions contribute to the development of problematic social media use. Addictive Behaviors Reports, 11, 100267. https://doi.org/10.1016/j.abrep.2020.100267.

Fioravanti, G., Primi, C., \& Casale, S. (2013). Psychometric evaluation of the generalized problematic Internet use scale 2 in an Italian sample. Cyberpsychology Behavior and Social Networking, 16(10), 761-766. https://doi.org/10.1089/cyber. 2012.0429.

Fried, E. I., Eidhof, M. B., Palic, S., Costantini, G., Huisman-van Dijk, H. M., Bockting, C. L. H., .. Karstoft, K.-I. (2018). Replicability and generalizability of posttraumatic stress disorder (PTSD) networks: A cross- cultural Multisite study of PTSD symptoms in four Trauma patient samples. Clinical Psychological Science, 6(3), 335-351. https://doi.org/10.1177/ 2167702617745092.

Gamez-Guadix, M., Orue, I., \& Calvete, E. (2013). Evaluation of the cognitive-behavioral model of generalized and problematic Internet use in Spanish adolescents. Psicothema, 25(3),299-306. https://doi.org/10.7334/psicothema2012.274.

Gamez-Guadix, M., Villa-George, F. I., \& Calvete, E. (2012). Measurement and analysis of the cognitive-behavioral model of generalized problematic Internet use among Mexican adolescents. Journal of Adolescence, 35(6), 1581-1591. https://doi.org/ 10.1016/j.adolescence.2012.06.005.

Griffiths, M. (1995). Technological addictions. Clinical Psychology Forum, 76, 14-14. Retrieved from https://shop.bps.org.uk/ clinical-psychology-forum-no-76-february- 1995.

Griffiths, M. (2005). A 'components' model of addiction within a biopsychosocial framework. Journal of Substance Use, 10(4), 191-197. https://doi.org/10.1080/14659890500114359.

Griffiths, M. D. (2009). Minimizing harm from gambling: What is the gambling industry's role? Addiction, 104(5), 696-697. https://doi.org/10.1111/j.1360-0443.2009.02499.x.

Griffiths, M. D. (2010). The role of context in online gaming excess and addiction: Some case study evidence. International Journal of Mental Health and Addiction, 8(1), 119-125. https://doi.org/ 10.1007/s11469-009-9229-x.

Griffiths, M. D. (2013). Social networking addiction: Emerging themes and issues. Journal of Addiction Research \& Therapy, 4, e118. https://doi.org/10.4172/2155-6105.1000e118.

Haslbeck, J. M. B. (2020). Mgm. Estimating time-varying k-order mixed graphical models (R package version 1.2-9) [Computer 
software]. Retrieved from https://cran.r-project.org/web/ packages/mgm/mgm.pdf.

Haslbeck, J. M. B., \& Waldorp, L. J. (2018). How well do network models predict observations? On the importance of predictability in network models. Behavior Research Methods, 50(2), 853-861. https://doi.org/10.3758/s13428-017-0910-x.

He, Q., Turel, O., \& Bechara, A. (2017). Brain anatomy alterations associated with Social Networking Site (SNS) addiction. Scientific Reports, 7(1), 45064. https://doi.org/10.1038/srep45064.

Huang, S., Lai, X., Xue, Y., Zhang, C., \& Wang, Y. (2020). A network analysis of problematic smartphone use symptoms in a student sample. Journal of Behavioral Addictions. https://doi. org/10.1556/2006.2020.00098.

Jolliff, A. F., Moreno, M. A., \& D’Angelo, J. (2020). The mediating role of depressive and anxiety symptoms in the association between obesity and problematic social media use in young adults. Obesity Science and Practice, 6(5), 454-459. https://doi. org/10.1002/osp4.434.

Jones, P. J. (2020). Network tools: Tools for identifying important nodes in networks (R package version 1.2.3) [Computer software]. Retrieved from https://cran.r-project.org/web/packages/ networktools/networktools.pdf.

Kardefelt-Winther, D. (2014). A conceptual and methodological critique of internet addiction research: Towards a model of compensatory internet use. Computers in Human Behavior, 31, 351-354. https://doi.org/10.1016/j.chb.2013.10.059.

Kurcaburun, K., Kokkinos, C. M., Demetrovics, Z., Király, O., Griffiths, M. D., \& Çolak, T. S. (2019). Problematic online behaviors among adolescents and emerging adults: Associations between cyberbullying perpetration, problematic social media use, and psychosocial factors. International Journal of Mental Health and Addiction, 17(4), 891-908. https://doi.org/10.1007/ s11469-018-9894-8.

Levinson, C. A., Zerwas, S., Calebs, B., Forbush, K., Kordy, H., Watson, H., .. Bulik, C. M. (2017). The core symptoms of bulimia nervosa, anxiety, and depression: A network analysis. Journal of Abnormal Psychology, 126(3), 340-354. https://doi. org/10.1037/abn0000254.

Lim, M. S. M., Cheung, F. Y. L., Kho, J. M., \& Tang, C. S. K. (2020). Childhood adversity and behavioural addictions: The mediating role of emotion dysregulation and depression in an adult community sample. Addiction Research \& Theory, 28(2), 116123. https://doi.org/10.1080/16066359.2019.1594203.

Marchetti, I. (2019). Hopelessness: A network analysis. Cognitive Therapy and Research, 43(3), 611-619. https://doi.org/10.1007/ s10608-018-9981-y.

Marino, C., Vieno, A., Altoè, G., \& Spada, M. (2016). Factorial validity of the problematic Facebook use scale for adolescents and young adults. Journal of Behavioral Addictions, 6(1), 5-10. https://doi.org/10.1556/2006.6.2017.004.

Moretta, T., \& Buodo, G. (2018). Modeling Problematic Facebook Use: Highlighting the role of mood regulation and preference for online social interaction. Addictive Behaviors, 87, 214-221. https://doi.org/10.1016/j.addbeh.2018.07.014.

Mullarkey, M. C., Marchetti, I., \& Beevers, C. G. (2019). Using network analysis to identify central symptoms of adolescent depression. Journal of Clinical Child \& Adolescent Psychology, 48(4), 656-668. https://doi.org/10.1080/15374416.2018.1437735.
Muthén, B. (1984). A general structural equation model with dichotomous, ordered categorical, and continuous latent variable indicators. Psychometrika, 49(1), 115-132. https://doi.org/ 10.1007/BF02294210.

Pontes, H. M., Caplan, S. E., \& Griffiths, M. D. (2016). Psychometric validation of the generalized problematic Internet use scale 2 in a Portuguese sample. Computers in Human Behavior, 63, 823-833. https://doi.org/10.1016/j.chb.2016.06.015.

Reer, F., Festl, R., \& Quandt, T. (2020). Investigating problematic social media and game use in a nationally representative sample of adolescents and younger adults. Behaviour and Information Technology. https://doi.org/10.1080/0144929X.2020.1724333.

Revelle, W. (2020). Psych. Procedures for psychological, psychometric, and personality research ( $\mathrm{R}$ package version 1.9.12.31) [Computer software]. Retrieved from https://cran.rproject.org/ web/packages/psych/psych.pdf.

Rosseel, Y., Jorgensen, T. D., Rockwood, N., Oberski, D., Byrnes, J., Vanbrabant, L. ... Du, H. (2020). Lavaan. Latent variable analysis ( $\mathrm{R}$ package version 0.6-7) [Computer software]. Retrieved from https://cran.r-project.org/web/packages/lavaan/ lavaan.pdf.

Rothen, S., Briefer, J. F., Deleuze, J., Karila, L., Andreassen, C. S., Achab, S.,... Billieux, J. (2018). Disentangling the role of users' preferences and impulsivity traits in problematic Facebook use. Plos One, 13(9), e0201971. https://doi.org/10.1371/journal. pone.0201971.

Schmittmann, V. D., Cramer, A. O. J., Waldorp, L. J., Epskamp, S., Kievit, R. A., \& Borsboom, D. (2013). Deconstructing the construct: A network perspective on psychological phenomena. New Ideas in Psychology, 31(1), 43-53. https://doi.org/10.1016/j. newideapsych.2011.02.007.

Shaffer, H. J., Hall, M. N., \& Vander Bilt, J. (2000). "Computer addiction": A critical consideration. American Journal of Orthopsychiatry, 70(2), 162-168. https://doi.org/10.1037/ h0087741.

Shapira, N. A., Lessig, M. C., Goldsmith, T. D., Szabo, S. T., Lazoritz, M., Gold, M. S., \& Stein, D. J. (2003). Problematic internet use: Proposed classification and diagnostic criteria. Depression and Anxiety, 17(4), 207-216. https://doi.org/10.1002/da.10094.

Shensa, A., Escobar-Viera, C. G., Sidani, J. E., Bowman, N. D., Marshal, M. P., \& Primack, B. A. (2017). Problematic social media use and depressive symptoms among U.S. Young adults: A nationally-representative study. Social Science \& Medicine, 182, 150-157. https://doi.org/10.1016/j.socscimed.2017.03.061.

Spada, M. M., Caselli, G., Nikčević, A. V., \& Wells, A. (2015). Metacognition in addictive behaviors. Addictive Behaviors, 44, 9-15. https://doi.org/10.1016/j.addbeh.2014.08.002.

Su, W., Han, X., Jin, C., Yan, Y., \& Potenza, M. N. (2019). Are males more likely to be addicted to the internet than females? A meta-analysis involving 34 global jurisdictions. Computers in Human Behavior, 99, 86-100. https://doi.org/10.1016/j.chb. 2019.04.021.

Tabachnick, B. G., \& Fidell, L. S. (2014). Using multivariate statistics (6th ed.). Harlow, UK: Pearson Education Limited.

Valente, T. W. (2012). Network interventions. Science, 337(6090), 49. https://doi.org/10.1126/science.1217330.

Varkaris, E., \& Neuhofer, B. (2017). The influence of social media on the consumers' hotel decision journey. Journal of Hospitality 
and Tourism Technology, 8(1), 101-118. https://doi.org/10. 1108/JHTT-09-2016-0058.

da Veiga, G. F., Sotero, L., Pontes, H. M., Cunha, D., Portugal, A., \& Relvas, A. P. (2019). Emerging adults and Facebook use: The validation of the bergen Facebook addiction scale (BFAS). International Journal of Mental Health and Addiction, 17(2), 279294. https://doi.org/10.1007/s11469-018-0018-2.

Walther, J. B. (1996). Computer mediated communication: Impersonal, interpersonal, and hyperpersonal interaction. Communication Research, 23, 3-43, https://doi.org/10.1177/ 009365096023001001.
Wong, H. Y., Mo, H. Y., Potenza, M. N., Chan, M. N. M., Lau, W. M., Chui, T. K.,... Lin, C. Y. (2020). Relationships between severity of internet gaming disorder, severity of problematic social media use, sleep quality and psychological distress. International Journal of Environmental Research and Public Health, 17(6), Article 1879. https://doi.org/10.3390/ ijerph17061879.

Ye, Y., \& Lin, L. (2015). Examining relations between locus of control, loneliness, subjective well-being, and preference for online social interaction. Psychological Reports, 116(1), 164175. https://doi.org/10.2466/07.09.PR0.116k14w3. 